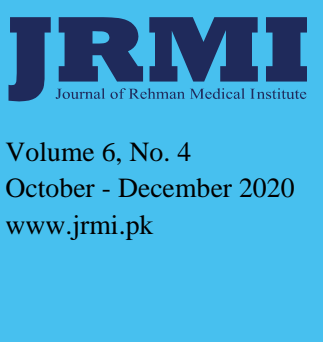

Submitted

November 22, 2020

Accepted

December 15, 2020

Author Information

Dr. Saqib Aziz Dawar

Trainee Medical officer,

Department of ENT Unit-A,

Hayatabad Medical Complex,

Peshawar.

(Corresponding Author)

Email:

dr.saqib.aziz.dawar@gmail.co

\section{Dr. Saba Rehman}

Dr. Humera Khan Dawar

Postgraduate Trainees

Department of Pediatrics,

Rehman Medical Institute,

Peshawar, Khyber

Pakhtunkhwa, Pakistan.

Dr. Abid Salahuddin

Consultant Pediatrician,

Rehman Medical Institute,

Peshawar.

Dr. Aziz Khan Dawar

Consultant ENT Surgeon,

Rehman Medical Institute,

Peshawar.

Citation: Dawar SA, Rehman S, Dawar HK, Salahuddin A,

Dawar AK. Outcome of tonsillectomy in children without the use of postoperative antibiotics at two tertiary care hospitals of Peshawar. J Rehman Medical Inst. 2020 Oct-Dec;6(4):21-3.

\title{
Outcome of tonsillectomy in children without the use of postoperative antibiotics at two tertiary care hospitals of Peshawar
}

\author{
Saqib Aziz Dawar, Saba Rehman, Humera Khan Dawar, Abid Salahuddin, Aziz Khan Dawar
}

\begin{abstract}
Introduction: Overuse of antibiotics can lead to antimicrobial resistance and unnecessary costs. Although early studies reported improved outcomes following use of perioperative antibiotics for tonsillectomy, more recent studies have not been able to demonstrate a significant benefit on post tonsillectomy morbidity.
\end{abstract}

Objective: To determine the need for postoperative antibiotics in children undergoing tonsillectomy under aseptic conditions at two tertiary care hospitals of Peshawar.

Materials \& Methods: Children aged 5-14 years admitted to the departments of Otorhinolaryngology-A unit of Hayatabad Medical Complex and Rehman Medical Institute, Peshawar from March 01, 2018 to September 30, 2018 for recurrent sore throat and recurrent quinsy were included in this quasi-experimental study based on prospective data collection and convenience sampling. Children with blood dyscrasias, upper and lower respiratory tract infections, and cardiopulmonary diseases were excluded. Routine preoperative investigations were done, and all were given postoperative analgesics. The patients were divided into two consecutive groups of 60 each; Group-A was given Co-amoxiclav $20 \mathrm{mg} / 5 \mathrm{mg} / \mathrm{kg} /$ day for 10 days and GroupB was not given any antibiotic. During their stay in the hospital and on follow up they were asked about pain via Visual Analogue Scale, and presence of fever and/or bleeding were documented.

Results: Of 120 children, 50 (41.6\%) were males and 70 $(58.4 \%)$ were females, of ages $05-14$ years; 01(1.6\%) from Group-A and 01(1.6\%) from Group-B presented with reactionary hemorrhage. However, 01(1.6\%) from Group-A and 25(40\%) from Group-B presented with secondary hemorrhage for which they were readmitted and put on injectable antibiotics. Similarly, 05(8.3\%) from Group-A and 14(23.3\%) from Group-B presented with pain for which pain killers were prescribed.

Conclusion: Post tonsillectomy antibiotics may have a role in reducing the morbidities associated with the procedure in our setup.

Keywords: Tonsillectomy; Postoperative Infections: Antibiotic Resistance; Hemorrhage.

The authors declared no conflict of interest. All authors contributed substantially to the planning of research, data collection, data analysis, and write-up of the article, and agreed to be accountable for all aspects of the work.

\section{INTRODUCTION}

Recurrent tonsillitis is a common indication for tonsillectomy in adults and children. ${ }^{1}$

Tonsillitis can cause significant illness and can be diagnosed by a complete history and clinical examination. A mild discomfort in the throat arising from tonsils is not an indication for tonsillectomy. ${ }^{2}$

An overuse of antibiotics can lead to a lot of antimicrobial resistance and unnecessary costs. ${ }^{3-5}$ Antibiotics are not used postoperatively in some countries. ${ }^{6}$ Surgical patients account for approximately $40 \%$ of antibiotic use in children's hospitals, ${ }^{7}$ and tonsillectomy is the second most common pediatric surgery, with more than 500,000 performed annually in the United States. ${ }^{8} \mathrm{~A}$ survey of otolaryngologists in the United States ${ }^{9}$ showed that $79 \%$ reported routine prescribing of antibiotics following tonsillectomy, and a recent retrospective review of 34 US children's hospitals ${ }^{10}$ showed that the rate of antibiotic use ranged from $2.7 \%$ to $92.6 \%$. On the contrary, only $10 \%$ of ENT specialists in the United Kingdom report using antibiotics for pediatric tonsillectomy. ${ }^{11}$

Although early studies reported that use of perioperative antibiotics for tonsillectomy was associated with improved outcomes, ${ }^{6,12}$ more recent studies have not been able to demonstrate a significant benefit on post tonsillectomy morbidity. ${ }^{13}$ There are various methods of tonsillectomy, the most common being the dissection method. ${ }^{12}$ This study was conducted to determine the need for postoperative antibiotics in patients undergoing tonsillectomy under aseptic conditions.

\section{MATERIALS \& METHODS}

One hundred and twenty patients presenting with recurrent sore throat (at least 6-7 episodes per year for more than one year) and recurrent quinsy were included in this quasi-experimental study on Inpatient basis from March 01, 2018 to September 30, 2018 in the Department of Otorhinolaryngology-A unit of Hayatabad Medical Complex and Rehman Medical Institute Peshawar, based on prospective data collection and convenience sampling. 
Children with blood dyscrasias, upper and lower respiratory tract and cardiopulmonary diseases were excluded from the study. Routine preop investigations like Fasting Blood Glucose, Coagulation Profile and Virology were done. Hemostasis was secured using bipolar or with silk-1 if needed and all were given post-operative analgesics.

The patients were divided into two groups of 60 patients each, to form test (Group-A) and control (Group-B) groups; one group was dealt with at a time, the other subsequently. Initially, GroupA was given Co-Amoxiclav $20 \mathrm{mg} / 5 \mathrm{mg} / \mathrm{kg} /$ day for 10 days, followed by Group-B who was not given any antibiotic. During their stay in the hospital and on follow up they were asked about pain via Visual Analogue Scale (VAS) and were asked to document any fever and bleeding.

\section{RESULTS}

Of 120 subjects, $50(41.6 \%)$ were males and 70 (58.4\%) females with ages from 05-14 years. The age and gender are shown in Table 1.

Table 1: Demographic data of subjects $(n=120)$.

\begin{tabular}{|c|l|c|c|}
\hline$\#$ & $\begin{array}{c}\text { Demographic } \\
\text { Variables }\end{array}$ & Frequency & Percentage \\
\hline 1. & Gender & 50 & 41.6 \\
& Male & 70 & 58.4 \\
\hline 2. & Female & & \\
& $05-10$ & 43 & 35.83 \\
& $11-14$ & 77 & 64.17 \\
\hline
\end{tabular}

The complications are shown in Table 2.

Reactionary hemorrhage occurred in 01(1.6\%) from Group-A and $01(1.6 \%)$ from Group-B. However, 01(1.6\%) from Group-A and $25(40 \%)$ from Group-B presented with secondary hemorrhage for which they were readmitted and put on injectable antibiotics. In addition, 05(8.3\%) from Group-A and 14(23.3\%) from Group-B presented with pain for which pain killers were prescribed.

Table 2: Outcomes of patients ( $n=160$ each group).

\begin{tabular}{|c|l|c|c|}
\hline$\#$ & \multicolumn{1}{|c|}{ Complications } & $\begin{array}{c}\text { Group-A } \\
\mathbf{n}(\boldsymbol{\%})\end{array}$ & $\begin{array}{c}\text { Group-B } \\
\mathbf{n}(\boldsymbol{\%})\end{array}$ \\
\hline 1. & Reactionary hemorrhage & $01(1.6 \%)$ & $01(1.6 \%)$ \\
\hline 2. & Secondary hemorrhage & $01(1.6 \%)$ & $25(40 \%)$ \\
\hline 3. & Pain & $05(8.3 \%)$ & $14(23.3 \%)$ \\
\hline 4. & Fever & 0 & 0 \\
\hline
\end{tabular}

\section{DISCUSSION}

In this quasi-experimental study, the result of post tonsillectomy regimens with and without the use of antibiotics were studied to determine the need for prescribing such antibiotics in routine. Tonsillectomy is a common procedure for chronic tonsillitis, and significant complications like bleeding can occur postoperatively. ${ }^{1}$ Some authors advocate the use of antibiotics while others while others are against it. ${ }^{6}$ A study by Montague et $\mathrm{al}^{14}$ showed an incidence of reactionary hemorrhage to be $1 \%$ and $1.5 \%$ respectively while in the present setup it was $1-2 \%$ which shows satisfactory results. A study by Qais et $\mathrm{al}^{15}$ noted secondary hemorrhage up to $7.4 \%$; the secondary hemorrhage in our setup was $40 \%$ for which the patients were given I/V antibiotics. Thus, it shows that if proper sterilization and aseptic techniques are applied, the risk of postoperative morbidity is decreased.

\section{CONCLUSION}

The need for post tonsillectomy antibiotics can be justified as they helped reduce morbidity in children for whom they were prescribed, so that there were lesser complications compared to the control group who were not given postoperative antibiotics.

\section{LIMITATIONS}

The study had several potential limitations since this study included patients from a single health care network in Khyber Pakhtunkhwa province and, therefore, might not be generalizable to all children undergoing tonsillectomy.

Moreover, the present study was meant to be a pilot quasiexperimental study, to determine at a preliminary level, the need for post tonsillectomy antibiotics despite the settings of tertiary care hospitals using standard aseptic and operative techniques. It would be far fetched to extend the results to remote areas of the province or the rest of the country, where smaller level hospitals may not be able to provide the necessary levels of surgical expertise or aseptic standards that were adopted in these two large tertiary care hospitals.

\section{RECOMMENDATIONS}

Based on results of the present study, it can be recommended that antibiotics should be used in routine after tonsillectomy, particularly in remote settings to reduce the morbidity associated with the procedure.

\section{REFERENCES}

1. Connon CR. The efficacy of a single dose antibiotic regimen in adults undergoing tonsillectomy. J Med Assoc. 2007;37:81721.

2. Lee WC, Duigan MC, Walsh RM, Mc RaeMoor JR. An Audit of prophylactic antibiotic treatment following tonsillectomy in children. J Laryngol Otol. 2006;110:357-9.

3. Vaz LE, Kleinman KP, Raebel MA, Nordin JD, Lakoma MD, Dutta-Linn MM et al. Recent trends in outpatient antibiotic use in children. Pediatrics. 2014;133(3):375-85.

4. Marr JJ, Moffat HL, Kunin CM. Guidelines for improving the use of antimicrobial agents in hospitals: a statement by the Infectious Diseases Society of America. J Infect Dis. 1988;157(5):869-76.

5. Shlaes DM, Gerding DN, John JF Jr, Craig WA, Bornstein DL, Duncan RA, et al. Society for Healthcare Epidemiology of America and Infectious Diseases Society of America Joint Committee on the Prevention of Antimicrobial Resistance: guidelines for the prevention of antimicrobial resistance in hospitals. Clin Infect Dis 1997;25(3):584-99.

6. Telian SA, Handler SD, Fisher GR, Baranak CC, Watmore RF, Potsic WP. The effect of antibiotic therapy on recovery after tonsillectomy in children. A controlled study. Arch Otolaryngol Head Neck Surg. 1986 Jun;112(6):610-5.

7. Gerber JS, Kronman MP, Ross RK, Hersh AL, Newland JG, Metjian TA, et 
al. Identifying targets for antimicrobial stewardship in children's hospitals. Infect Control Hosp Epidemiol. 2013;34(12):1252-8.

8. Cullen KA, Hall MJ, Golosinskiy A. Ambulatory surgery in the United States, 2006. Natl Health Stat Report. 2009;(11):1-25.

9. Krishna P, LaPage MJ, Hughes LF, Lin SY. Current practice patterns in tonsillectomy and perioperative care. Int J Pediatr Otorhinolaryngol. 2004;68(6):77984.

10. Mahant S, Keren R, Localio R, Luan X, Song L, Shah SS, et al. Variation in quality of tonsillectomy perioperative care and revisit rates in children's hospitals. Pediatrics. 2014;133(2):280-8.

11. Dhiwakar M, Brown PM. Are adjuvant therapies for tonsillectomy evidence based? J Laryngol Otol. 2005;119(8):6149.

12. Grandis JR, Johnson JT, Vickers RM, Yu VL, Wagener MM, Wagner RL, et al. The efficacy of perioperative antibiotic therapy on recovery following tonsillectomy in adults: randomized double-blind placebocontrolled trial. Otolaryngol Head Neck Surg. 1992;106(2):137-42.

13. Guerra MM, Garcia E, Pilan RR, Rapoport PB, Campanholo CB, Martinelli EO. Antibiotic use in post- adenotonsillectomy morbidity: a randomized prospective study. Braz J Otorhinolaryngol. 2008;74(3):337-41.

14. Montague ML, Lee MSW, Hussain SSM. Post Tonsillectomy hemorrhage-impact of altered practice. Otolaryngology Head Neck Surg. 2002;127:195.

15. Aljfout Q, Alississ A, Rashdan H, Maita A, Saraireh M. Antibiotics for PostTonsillectomy Morbidity: Comparative Analysis of a Single Institutional Experience. J Clin Med Res. 2016;8(5):385-8. 